\title{
PENERAPAN METODE DIAGRAM SEBAGAI BAHASA PADA TRANSFORMASI GUBAHAN MASSA RUANG SOSIAL INTERKULTURAL SEBAGAI TEMPAT KETIGA DI KELURAHAN SELONG
}

\author{
Rivanto $^{1)}$, Suwardana Winata ${ }^{2)}$ \\ 1)Program Studi S1 Arsitektur, Fakultas Teknik, Universitas Tarumanagara, \\ Rivanxp9@gmail.com \\ 2) Program Studi S1 Arsitektur, Fakultas Teknik, Universitas Tarumanagara, Danarsitek@gmail.com
}

\begin{abstract}
Abstrak
Ruang Sosial Interkultural merupakan suatu wadah yang dirancang sebagai respon dari adanya jarak sosial yang terjadi di Kelurahan Selong, Kebayoran Baru, Jakarta Selatan. Lokasi tapak perancangan berada di jalan Senopati. Secara demografis, jalan ini "membagi" dominasi fungsi dan figur di dalam kawasan tersebut. Hal ini membuat jarak sosial yang semakin meningkat antar neighborhood dengan karakter masyarakat yang memiliki keberagaman budaya. Sehingga, diperlukannya suatu wadah sebagai dwelling pada kawasan tersebut. Agar, meningkatnya relasi dan kegiatan interaksi sosial antar neighborhood di Kelurahan Selong. Proyek ini dirancang sebagai wadah yang memudahkan berlangsungnya kegiatan interaksi sosial antar neighborhood di Kelurahan Selong. Media seni pertunjukan digunakan sebagai program, baik itu pembelajaran maupun menyaksikan pertunjukan teater, tari maupun musik. Dimana, secara tidak langsung akan memunculkan metode pembelajaran trialogis dari interaksi yang terjadi antar figur di dalam Ruang Sosial Interkultural. Program seni pertunjukan diangkat sebagai konsep transformasi bentuk. Yaitu, tarian balet yang digunakan sebagai media pembentukan komposisi massa. Hal ini dikarenakan, tarian dalam program proyek perancangan menjadi dasar dari program seni pertunjukan, yaitu gerak. Tarian balet digunakan sebagai media transformasi bentuk dikarenakan balet menjadi tari yang berpengaruh pada tarian lain secara global dan kaitannya dengan isu interkultural. Gerak dalam tarian diterjemahkan kedalam notasi laban, kemudian dilakukan dekonstruksi, superimposisi, dan penyesuaian dengan program, hingga mendapatkan komposisi massa yang memiliki kesesuaian kekokohan, keberhasilan bangunan dalam memenuhi fungsi kegiatannya, serta aspek keindahannya. Oleh karena itu, metode diagram digunakan untuk mempermudah penyampaian informasi dari proses transformasi bentuk yang terjadi pada proyek Ruang Sosial Interkultural sebagi tempat ketiga di Kelurahan Selong.
\end{abstract}

\section{Kata kunci: demografis; diagram; dwelling; neighborhood; tarian}

\begin{abstract}
Intercultural Social Space is a space that designed in response to the social distance that occurs in the Selong Village, Kebayoran Baru, South Jakarta. It's located on Senopati street. Demographically, this site divides the dominance of function and figures within the area. This increasing the social distance between the neighborhood and the character of the people who have the cultural diversity. So, this needs a space as a dwelling in the area. So that, it increase relations and social interactions activities between neighborhood in the Selong Village. This project was designed for a space that facilitate the ongoing social interaction activities between neighborhood in the Selong Village. Performing arts is used as a program, whether it's for learning or for watching theatre, dance or music performances. Which, indirectly will bring up the method of trialogical learning of interactions that occur between figures in the Intercultural Social Space. The performing arts program was appointed as a concept of shape transformation. Specifically, the ballet
\end{abstract}


that is used as a medium for the formation of mass compositions. This because, dance in the design project program is the basis of the performing arts, namely motion. Ballet used as a form of medium shape transformation because ballet is a dance that influences other dances globally and it's related to intercultural issues. The motion in the dance is translated into Laban notation, then it's deconstructed, superimposed, and it's adjusted with the program, to get a mass composition that has a suitability of sturdiness, and the success of the building in fulfilling the function of it's activities, as well as it's aesthetics. Therefore, the diagram method is used to facilitate the delivery of information from the elaboration of the shape transformation process that occurs in the Intercultural Social Space project as a third place in Selong Village.

Keywords: dance; demographic; diagram; dwelling; neighborhood

\section{PENDAHULUAN}

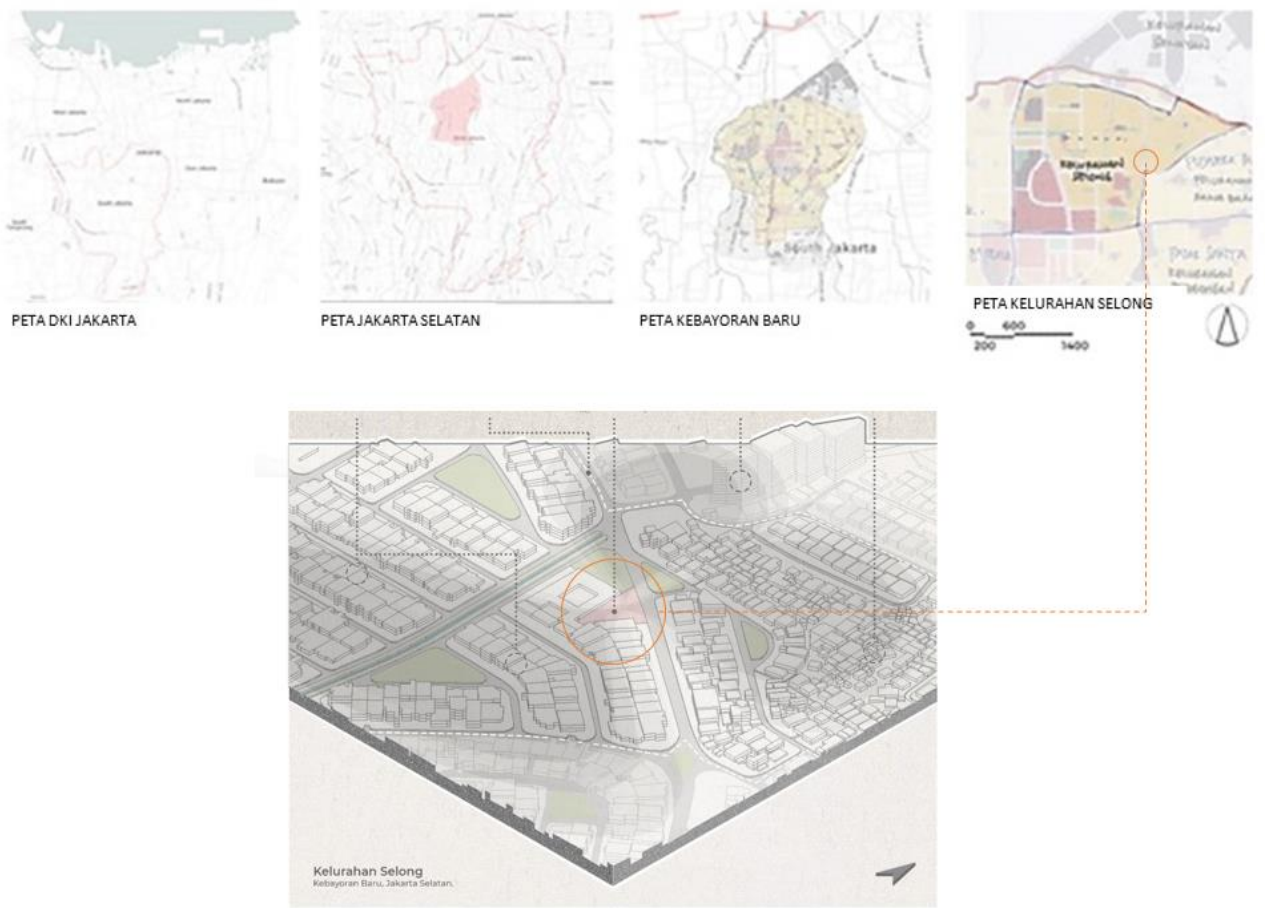

Gambar 1. Lokasi tapak terhadap Kota Jakarta.

Sumber: Dokumen Pribadi, 2020

Lokasi tapak yang dijadikan studi pada proyek ini berada di Jalan Senopati, Kelurahan Selong, Kebayoran Baru, Jakarta Selatan. Secara demografis, jalan ini "membagi" dominasi fungsi di kawasan tersebut. Pada bagian utara didominasi oleh kawasan bisnis perkantoran (CBD) dan hunian berupa kost yang mayoritasnya dihuni oleh ekspatriat dan pelaku bisnis lainnya. Sedangkan, pada bagian selatan didominasi oleh hunian dengan dihuni oleh kelompok masyarakat dengan penghasilan menengah atas dan atas, serta beberapa masyarakat di antaranya adalah pelaku bisnis, duta besar, ibu rumah tangga, pelajar, dan lainnya. Hal ini secara tidak langsung memberi jarak terhadap suatu "Neighborhood" dengan keberagaman budaya dan bahasa yang ada pada masyarakat yang tinggal di Kelurahan Selong. Menurut (Bennet, 1984) keberagaman budaya antar masyarakat memunculkan permasalahan interaksi sosial karena terdapat pandangan etnosentrik dimana adanya polarisasi perbedaan di antar masyarakat. Pandangan ini harus diubah menjadi pandangan etnorelatif untuk meningkatkan interaksi sosial yang terjadi di antar masyarakat Kelurahan Selong. Untuk merubah pandangan 
tersebut, menurut (Hakkarainen, 2009) dibutuhkan suatu program sebagai media pembelajaran secara trialogis.

Menurut Frederick Gibberd (1970) elemen yang paling dasar dalam sebuah neighborhood adalah dwelling. Dimana dalam merubah pandangan tersebut, dibutuhkan sebuah wadah sarana untuk berlangsungnya kegiatan interaksi sosial antar masyarakat. Oleh karena itu tujuan dari studi yang dilakukan pada proyek Ruang Sosial Interkultural adalah menentukan program yang tepat sasaran sebagai tempat ketiga yang menjadi dwelling sebagai elemen mendasar dari suatu neighborhood. Setelah mendapatkan program seni pertunjukan, gagasan konsep transformasi bentuk massa bangunan diangkat dari program tersebut. Seni pertunjukan yang dirancang sebagai program adalah pembelajaran maupun tempat untuk menyaksikan seni teater, tari, maupun musik. Tari dalam proyek ini menjadi dasar dari program seni pertunjukan yang ada yaitu gerak. Tarian balet digunakan sebagai media transformasi bentuk dikarenakan secara global, balet menjadi tari yang berpengaruh pada tarian lain secara global serta kaitannya dengan permasalahan interkultural. Proses transformasi bentuk yang dilakukan adalah menggunakan notasi laban yang diterjemahkan dari tarian balet, kemudian dilakukan dekonstruksi, superimposisi, dan penyesuaian dengan program terhadap hasil dari notasi laban yang terbentuk hingga mendapatkan komposisi massa yang memiliki kesesuaian dengan trinitas arsitektur. Oleh karena itu, metode diagram digunakan untuk mempermudah penyampaian informasi dari penjabaran proses transformasi bentuk yang terjadi pada proyek Ruang Sosial Interkultural sebagi tempat ketiga di Kelurahan Selong. Adapun rumusan masalah terkait bagaimana cara menentukan program yang tepat sasaran sebagai tempat ketiga yang memudahkan proses berinteraksi antar neighborhood di Kelurahan Selong dan bagaimana penerapan metode diagram sebagai bahasa pada proses transformasi gubahan massa dalam proyek Ruang Sosial Interkultural.

\section{KAJIAN LITERATUR}

\section{Space dan Place}

Istilah place erat kaitannya dengan teori space. Apabila space diartikan sebagai tiga dimensi yang membentuk place, dan place diartikan sebagai suasana dari sebuah karakter dari space. Pengertian place bukanlah sesuatu yang abstrak atau sekedar konsep, melainkan place adalah sebuah fenomena kehidupan yang mengandung unsur pengalaman langsung, mempunyai arti dan merupakan sesuatu yang nyata yang didalamnya terdapat aktivitas yang terjadi terus menerus. Keberadaan place penting karena merupakan sumber dari sebuah identitas yang menunjukkan eksistensi individu maupun komunitas, bahkan lebih dari itu, place mempunyai hubungan emosional sangat dalam dan psikologi, baik itu perorangan maupun komunitas (Larrice, Michael, Macdonald, \& Elizabeth, 2007).

\section{Third Place dan Neighborhood}

Istilah third place pada awalnya hanya mengarah kepada tempat-tempat hangout seperti kafe dan bar. Padahal istilah third place juga mengarah pada ruang-ruang terbuka kota, seperti taman kota, plaza, dan sidewalk dimana masyarakat dapat menghabiskan waktu untuk berkumpul dengan saudara atau teman-teman sambil menikmati suasana kota. Oleh Karena itu third place juga disebut sebagai a public meeting place. Sedangkan tempat tinggal mengidentifikasikan rumah yang disebut sebagai first place sedangkan tempat kerja sebagai second place. Pembangunan pemukiman yang individual mempengaruhi kehidupan sosial masyarakat. Menyebabkan diantara masyarakat tidak saling mengenal, meskipun berada di dalam satu lingkungan. Lingkungan pemukiman yang terbentuk terasa sangat membosankan dan mengisolasi masyarakat. Third place hadir dan diperlukan bagi masyarakat untuk melepaskan kepenatan yang berasal dari aktivitas sehari-hari pada first place dan second place. Third place memiliki karakter yang bersifat neutral, leveler, conversation, accessible and 
accommodation, regular, low profile, mood is playful, dan home away frome home. (Oldenburg, 1999).

Ali Madanipour (2003) melihat neighborhood sebagai sebuah komunitas ideal yang memiliki sense of community. Dalam sebuah neighborhood, komunitas menjadi faktor pembentuk utama, dimana manusia dilahirkan untuk berinteraksi dengan manusia lainnya, dan cenderung membentuk kelompok-kelompok sosial dengan tujuan yang relatif sama Jarak dan pola penempatan elemen pembentuk neighborhood akan menentukan, apakah dalam neighborhood tersebut akan terjadi interaksi antar penghuninya, yang secara tidak langsung akan menghidupkan lingkungannya. Frederick Gibberd (1970: 259-266) menyatakan bahwa elemen yang paling dasar dalam sebuah neighborhood adalah dwelling. Perumahan ataupun area hunian, bukan hanya merupakan sekumpulan rumah tetapi juga keberadaan sarana dan prasarananya. Sarana yang harus ada sebagai penunjang, antara lain adalah keberadaan open space dan social services sebagai pemenuhan kebutuhan sehari-hari. Social service yang paling umum adalah tersedianya sarana pendidikan (sampai dengan rentang usia 12 tahun) dan tempat belanja kebutuhan sehari-hari. Selain itu juga disediakan fasilitas berkumpul untuk individu yang tinggal berdekatan. Dalam penataan kawasan kota, neighborhood secara tidak langsung memiliki jarak yang memisahkan satu sama lain. Hal ini tidak berdampak terhadap interaksi sosial yang terjadi di antara masyarakatnya jika, keberadaan dwelling sebagai wadah untuk memudahkan sosialisasi antar masyarakatnya tersedia. Dwelling sebagai wadah sarana yang berupa open spaces dan social services sudah menjadi hal yang paling mendasar ada diantara komunitas atau neighborhood. Sebagai sarana untuk memudahkan interaksi yang terjadi, wadah tersebut dirancang dengan karakteristik dari third place sehingga semua kalangan masyarakat dapat berkumpul dalam wadah tersebut.

\section{Programming Framework}

(Pena \& Parshall, 2001: 12-25) menyebutkan 5 langkah yang menjadi titik fokus dalam menentukan sebuah program. Diantaranya adalah: menentukan tujuan, menentukan dan analisis fakta, menentukan dan menguji konsep dasar dari program, menentukan kebutuhan, dan menyatakan masalah. Adapun 4 (empat) pertimbangan dasar, diantaranya adalah: waktu, bentuk, ekonomi, dan waktu. Pertimbangan tersebut memiliki penjabaran sebagai berikut

a. Function: People, activities, relationships.

b. Form: Site, environment, quality.

c. Economy: Initial budget, operating costs, life cycle cost.

d. Time: Past, present, future.

Dari pertimbangan tersebut, framework untuk menentukan program terbentuk. Selanjutnya pertimbangan untuk menentukan program dilakukan analisis untuk menentukan tujuan hingga menyatakan permasalahan. (Pena \& Parshall, 2001: 30-32)

Tabel 1. Programming framework

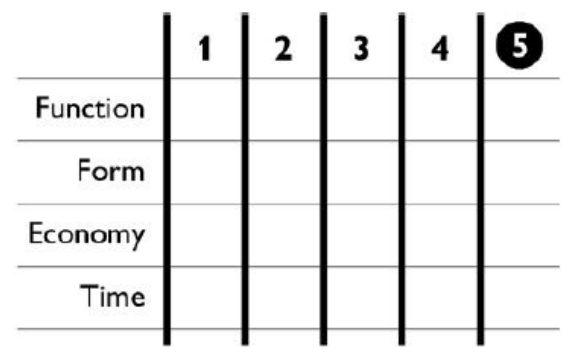

Sumber: Pena \& Parshall, 2001. 


\section{Diagram Sebagai Bahasa Arsitektur}

Membahas literasi visual yang diartikan menjadi "keaksaraan visual" (Dondis, 1974). Hal ini berarti, bahwa bahasa visual memiliki tata bahasa layaknya seperti bahasa verbal maupun tulisan. Bahasa visual dalam hal ini terbagi menjadi pemikiran visual dan komunikasi visual. Hal tersebut merujuk pada sebuah proses yang saling berkaitan. Bahasa visual menjadi media komunikasi yang kompleks dimana pembaca dari media visual dapat meluaskan pemikirannya terhadap informasi yang ingin disampaikan dari sebuah bahasa visual. Dalam arsitektur, diagram menjadi bahasa visual yang dijadikan media komunikasi untuk menyampaikan gagasan atau ide berpikir terhadap sesuatu yang ingin di informasikan. Ben van Berkel dan Caroline Bos merekomendasikan penggunaan diagram sebagai sarana berpikir yang abstrak tentang suatu kemungkinan dalam merepresentasikan sebuah informasi atau ide dari perancang.

Diagram digunakan sebagai sarana yang memudahkan penyampaian informasi kepada individu. Informasi ini disampaikan dengan gambar-gambar yang dapat di representasikan kembali oleh pengamat dan bahkan dapat dikembangkan dalam pemikiran dan pandangan ketika melihatnya. Hal ini diterapkan karena terdapat sebuah ide atau gagasan yang bersifat abstrak dan sulit dimengerti bila dijelaskan secara verbal. Penggabungan gambar, garis hayal yang terbentuk dari sebuah objek, menerjemahkan sebuah objek kedalam sebuah bentuk tertentu, dan sebagainya. Sehingga penggunaan metode diagram dapat membantu menerangkan informasi dari sebuah ide dan gagasan yang sifatnya abstrak menjadi lebih mudah dimengerti.

\section{METODE}

Setelah melakukan observasi langsung ke lapangan dan mencari data, fakta serta studi tentang kawasan di Kelurahan Selong, Kebayoran Baru. Langkah selanjutnya adalah melakukan riset program. Dalam hal ini, Programming Framework digunakan untuk mengetahui permasalahan yang terjadi dan menyatakan program. (Pena \& Parshall, 2001). Adapun langkah-langkah untuk melakukan programming diantaranya adalah: Menentukan tujuan, tujuan yang digunakan adalah karakter dari tempat ketiga itu sendiri.; Mengumpulkan dan melakukan analisis terhadap fakta yang ada di Kelurahan Selong; menentukan konsep yang akan dilakukan; menentukan kebutuhan untuk mencapai konsep; menemukan masalah. Adapun 4 (empat) pertimbangan dalam melakukan programming, yaitu: fungsi, bentuk, ekonomi, dan waktu. Selanjutnya langkah dan pertimbangan tersebut di masukan kedalam tabel programming kemudian menyatakan program.

Langkah selanjutnya adalah melakukan transformasi gubahan massa. Dalam hal ini, konsep Tarian dan Arsitektur di gunakan sebagai metode pembentukan massa bangunan. Ide ini diangkat dari penemuan program seni pertunjukan pada proyek Ruang Sosial Interkultural yang merujuk pada program seni tari. Tari balet digunakan sebagai media dalam pembentukan gubahan massa, kemudian dikerucutkan dengan kisah cerita Swan Lake yang umum digunakan sebagai koreo dalam tarian balet. Selanjutnya, dilakukan penjabaran terhadap 4 alur cerita swan lake dan menerjemahkan koreografi tarian balet cerita swan lake menjadi notasi laban. Dekonstruksi dilakukan pada notasi laban yang terbentuk dari kisah cerita swan lake terhadap visual yang terbentuk dari gerakan tari balet. Selanjutnya dilakukan penyesuaian aksis dengan tapak proyek. Setelah itu, langkah terakhir adalah melakukan superimposisi dan penyesuaian dari garis notasi laban yang telah digabung dari 4 alur cerita swan lake dengan program ruang yang diterjemahkan ruangnya menjadi 3 dimensi. Selanjutnya, keseluruhan studi dan transformasi bentuk massa di tuang kedalam bentuk diagram sehingga dapat memudahkan 
proses dalam mendapatkan bentuk yang memiliki kesesuaian secara kekokohan, keberlangsungan fungsi pada bangunan, dan memiliki keindahan bentuk.

\section{DISKUSI DAN HASIL}

Dari Beberapa teori para ahli, keberadaan dwelling sebagai wadah untuk memudahkan sosialisasi antar masyarakatnya tersedia. Dwelling sebagai wadah sarana yang berupa open spaces dan social services sudah menjadi hal yang paling mendasar ada diantara komunitas atau neighborhood. Sebagai sarana untuk memudahkan interaksi yang terjadi akibat adanya jarak sosial yang memisahkan beberapa neighborhood. Oleh karena itu, wadah tersebut dirancang dengan karakteristik dari third place sehingga semua kalangan masyarakat dapat berkumpul dalam wadah tersebut.

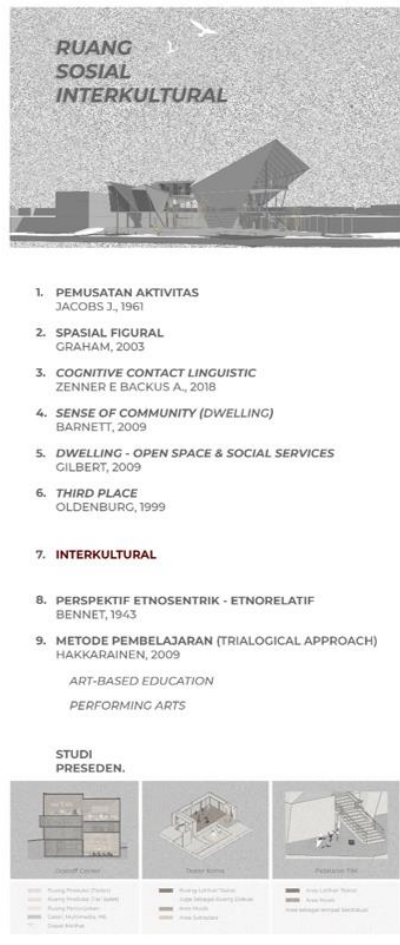

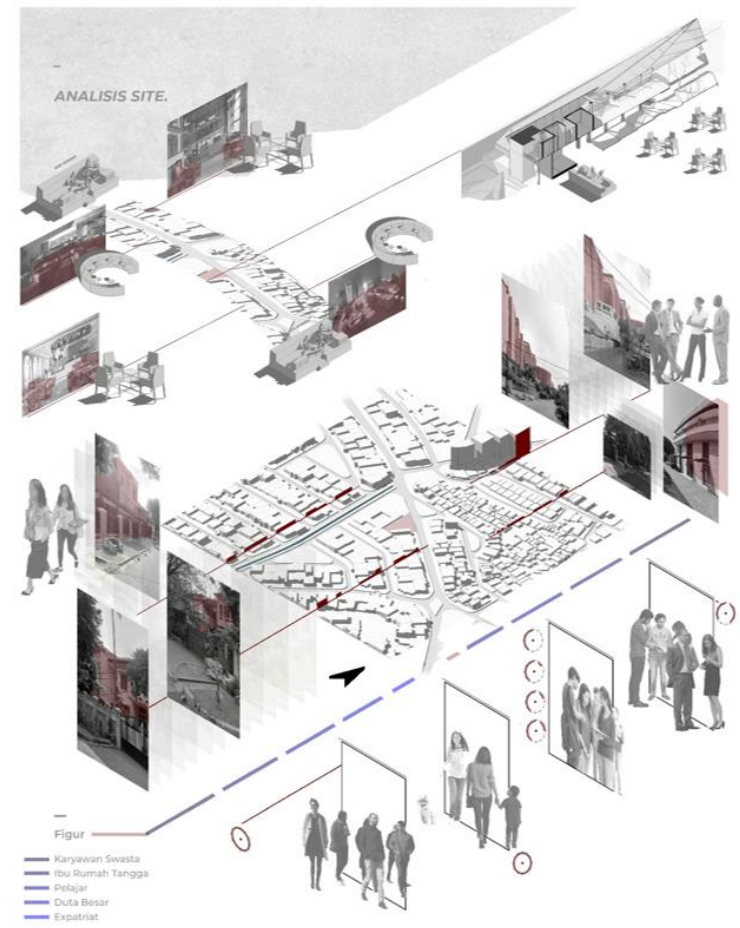

Gambar 2. Analisis tapak

Sumber: Dokumen Pribadi, 2020

Jalan Senopati yang berada di Kelurahan Selong, Kebayoran Baru, Jakarta Selatan secara demografisnya "membagi" dominasi neighborhood pada kawasan tersebut. Dalam satu sisi, terdapat permasalahan keragaman budaya interkultural antar masyarakat yang memunculkan pandangan etnosentik. Untuk menciptakan pandangan etnorelatif agar terciptanya interaksi sosial yang baik antar masyarakat di Kelurahan Selong, diperlukan sebuah wadah yang dapat menjadi dwelling diantara neighborhood. Oleh karena itu, Ruang Sosial Interkultural dirancang sebagai wadah interaksi yang menyatukan inidvidu melalui media seni pertunjukan yang secara tidak langsung memunculkan metode pembelajaran trialogis terkait bahasa antar individu dari interaksi yang terjadi antar individu di dalam Ruang Sosial Interkultural.

Dalam melakukan analisis program, Setelah melakukan observasi langsung ke lapangan dan mencari data, fakta serta studi tentang kawasan di Kelurahan Selong, Kebayoran Baru. Langkah selanjutnya adalah melakukan riset program. Adapun langkah-langkah untuk melakukan Programming diantaranya adalah: Menentukan tujuan, tujuan yang digunakan adalah karakter dari tempat ketiga itu sendiri.; Mengumpulkan dan melakukan analisis terhadap fakta yang ada di Kelurahan Selong; menentukan konsep yang akan dilakukan; menentukan kebutuhan untuk 
mencapai konsep; menemukan masalah. Serta terdapat 4 pertimbangan, yaitu: fungsi, bentuk, ekonomi, dan waktu. Selanjutnya langkah dan pertimbangan tersebut di masukan kedalam Programming Framework untuk mengetahui permasalahan yang terjadi dan menyatakan program. (Pena \& Parshall, 2001).

Tabel 2. Analisis permasalahan karakter neutral

\begin{tabular}{|c|c|c|c|c|c|}
\hline & Tujuan & Fakta & Konsep & Kebutuhan & Masalah \\
\hline Fungsi & Netral & Multikulturalisme & $\begin{array}{l}\text { Integrasi } \\
\text { keragaman } \\
\text { kultur }\end{array}$ & $\begin{array}{c}\text { Wadah } \\
\text { bersosialisasi }\end{array}$ & $\begin{array}{l}\text { Sistem } \\
\text { integrasi }\end{array}$ \\
\hline Bentuk & $\begin{array}{c}\text { Tempat yang } \\
\text { netral }\end{array}$ & $\begin{array}{c}\text { Pemusatan fungsi } \\
\text { yang kontras }\end{array}$ & $\begin{array}{c}\text { Terbuka untuk } \\
\text { semua } \\
\text { kalangan }\end{array}$ & $\begin{array}{c}\text { Tempat berada } \\
\text { diantara variasi } \\
\text { fungsi }\end{array}$ & $\begin{array}{c}\text { Bentuk yang } \\
\text { terbuka }\end{array}$ \\
\hline Ekonomi & - & - & - & - & - \\
\hline Waktu & - & - & - & - & - \\
\hline
\end{tabular}

Tabel 3. Analisis permasalahan karakter leveler

\begin{tabular}{|c|c|c|c|c|c|}
\hline & Tujuan & Fakta & Konsep & Kebutuhan & Masalah \\
\hline Fungsi & Leveler & $\begin{array}{l}\text { Variasi profesi yang } \\
\text { kontras }\end{array}$ & $\begin{array}{l}\text { Individu datang } \\
\text { memiliki } \\
\text { tujuan yang } \\
\text { sama }\end{array}$ & $\begin{array}{c}\text { Fungsi } \\
\text { berkaitan } \\
\text { dengan variasi } \\
\text { profesi }\end{array}$ & $\begin{array}{l}\text { Sistem } \\
\text { integrasi }\end{array}$ \\
\hline Bentuk & Leveler & $\begin{array}{c}\text { Variasi bentuk massa } \\
\text { bangunan yang } \\
\text { kontras }\end{array}$ & $\begin{array}{c}\text { Sebagai } \\
\text { tempat } \\
\text { bersosialisasi }\end{array}$ & $\begin{array}{l}\text { Pola yang } \\
\text { bersifat } \\
\text { interaksi }\end{array}$ & $\begin{array}{c}\text { Bentuk yang } \\
\text { terbuka }\end{array}$ \\
\hline Ekonomi & - & - & - & - & - \\
\hline Waktu & - & - & - & - & - \\
\hline
\end{tabular}

Sumber: Dokumen Pribadi, 2020.

Tabel 4. Analisis permasalahan karakter conversation

\begin{tabular}{|c|c|c|c|c|c|}
\hline & Tujuan & Fakta & Konsep & Kebutuhan & Masalah \\
\hline Fungsi & $\begin{array}{l}\text { Fungsi utama } \\
\text { untuk } \\
\text { percakapan }\end{array}$ & $\begin{array}{c}\text { Karakter sosial } \\
\text { yang kontras }\end{array}$ & $\begin{array}{c}\text { Mewadahi } \\
\text { percakapan } \\
\text { dengan program }\end{array}$ & $\begin{array}{c}\text { program yang } \\
\text { berinteraksi/ber } \\
\text { cakap }\end{array}$ & $\begin{array}{c}\text { Program, } \\
\text { menggunakan } \\
\text { percakapan }\end{array}$ \\
\hline Bentuk & $\begin{array}{c}\text { Membuat semua } \\
\text { kalangan saling } \\
\text { berinteraksi }\end{array}$ & $\begin{array}{c}\text { Pola hunian yang } \\
\text { kurang } \\
\text { berinteraksi }\end{array}$ & $\begin{array}{c}\text { Wadah agar } \\
\text { individu } \\
\text { berinteraksi dalam } \\
1 \text { tujuan }\end{array}$ & $\begin{array}{c}\text { Ruang } \\
\text { berinteraksi }\end{array}$ & $\begin{array}{l}\text { Bentuk ruang } \\
\text { yang efisien }\end{array}$ \\
\hline Ekonomi & - & - & - & - & - \\
\hline Waktu & - & - & - & - & - \\
\hline
\end{tabular}

Tabel 5. Analisis permasalahan karakter accessible

\begin{tabular}{|c|c|c|c|c|c|}
\hline & Tujuan & Fakta & Konsep & Kebutuhan & Masalah \\
\hline Fungsi & Accessible & $\begin{array}{c}\text { Variasi waktu } \\
\text { luang antar } \\
\text { individu }\end{array}$ & $\begin{array}{c}\text { Fungsi bisa } \\
\text { diakses kapanpun }\end{array}$ & $\begin{array}{l}\text { Program yang } \\
\text { tidak terikat } \\
\text { pada waktu }\end{array}$ & $\begin{array}{l}\text { Program yang } \\
\text { tidak } \\
\text { terganggu oleh } \\
\text { waktu }\end{array}$ \\
\hline Bentuk & Accessible & Dapat dengan & Memungkinkan & Site yang & Pencapaian \\
\hline
\end{tabular}




\begin{tabular}{|c|c|c|c|c|c|}
\hline & & mudah diakses & $\begin{array}{c}\text { akses dari banyak } \\
\text { arah }\end{array}$ & $\begin{array}{l}\text { mudah dicapai } \\
\text { dan efisien }\end{array}$ & $\begin{array}{l}\text { site mudah } \\
\text { (walkable) }\end{array}$ \\
\hline Ekonomi & Accessible & $\begin{array}{c}\text { Pendapatan } \\
\text { ekonomi beragam }\end{array}$ & $\begin{array}{l}\text { Meminimalisir/ } \\
\text { bahkan } \\
\text { menggratiskan } \\
\text { biaya program } \\
\text { utama }\end{array}$ & $\begin{array}{c}\text { Fungsi opsional } \\
\text { sebagai } \\
\text { pendapatan }\end{array}$ & $\begin{array}{l}\text { Keterkaitan } \\
\text { fungsi utama } \\
\text { dan fungsi } \\
\text { tambahan }\end{array}$ \\
\hline
\end{tabular}

Sumber: Dokumen Pribadi, 2020.

Tabel 6. Analisis permasalahan karakter regulars

\begin{tabular}{|c|c|c|c|c|c|}
\hline & Tujuan & Fakta & Konsep & Kebutuhan & Masalah \\
\hline Fungsi & Regulars & $\begin{array}{c}\text { Kelompok } \\
\text { dengan karakter } \\
\text { yang beragam }\end{array}$ & $\begin{array}{c}\text { Membuat antar } \\
\text { kelompok mudah } \\
\text { bersosial }\end{array}$ & $\begin{array}{c}\text { Fungsi yang } \\
\text { membuat orang } \\
\text { bersosial }\end{array}$ & $\begin{array}{l}\text { Program yang } \\
\text { memungkinkan }\end{array}$ \\
\hline Bentuk & Regulars & $\begin{array}{l}\text { Perbedaan fungsi } \\
\text { yang terpusat }\end{array}$ & $\begin{array}{l}\text { Mengumpulkan } \\
\text { kelompok di } 1 \text { tempat }\end{array}$ & $\begin{array}{l}\text { Pola ruang agar } \\
\text { memungkinkan } \\
\text { interaksi tidak } \\
\text { hanya pada } \\
\text { kelompok tertentu }\end{array}$ & $\begin{array}{l}\text { Memungkinkan } \\
\text { individu agar } \\
\text { saling berbaur }\end{array}$ \\
\hline Ekonomi & Regulars & $\begin{array}{c}\text { Tingkat ekonomi } \\
\text { yang kontras } \\
\text { beragam }\end{array}$ & $\begin{array}{c}\text { Meminimalisir biaya } \\
\text { pada pembayaran } \\
\text { main program }\end{array}$ & $\begin{array}{l}\text { Program opsional } \\
\text { untuk pemasukan }\end{array}$ & $\begin{array}{c}\text { Kemungkinan } \\
\text { berkelompok } \\
\text { antar kesamaan } \\
\text { profesi }\end{array}$ \\
\hline
\end{tabular}

Sumber: Dokumen Pribadi, 2020.

Tabel 7. Analisis permasalahan karakter low-profile

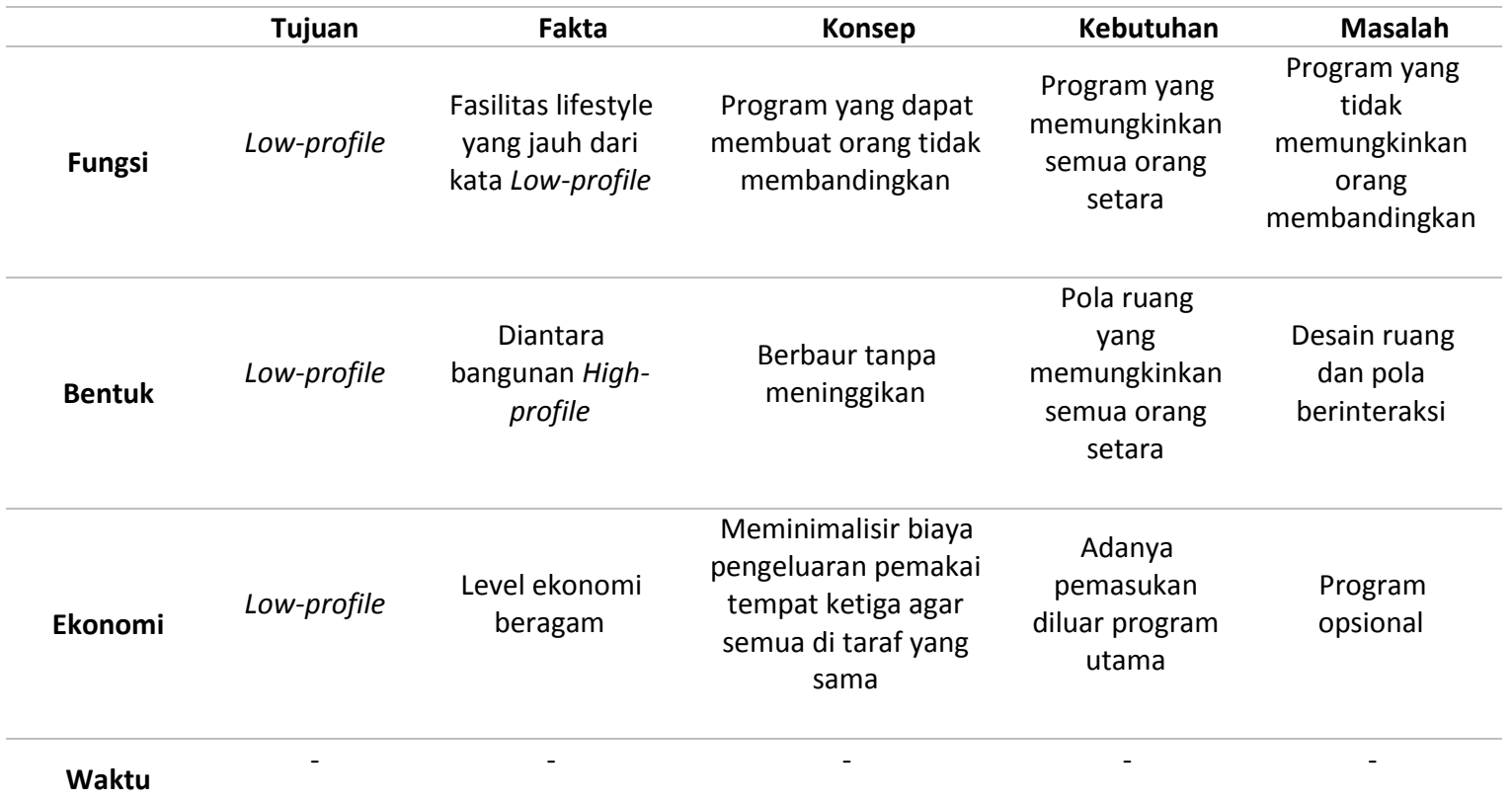

Sumber: Dokumen Pribadi, 2020. 
Tabel 8. Analisis permasalahan karakter playful

\begin{tabular}{|c|c|c|c|c|c|}
\hline & Tujuan & Fakta & Konsep & Kebutuhan & Masalah \\
\hline Fungsi & Playful & $\begin{array}{l}\text { Hobi yang } \\
\text { bervariasi dan } \\
\text { kontras }\end{array}$ & $\begin{array}{l}\text { Mengintegrasikan hobi } \\
\text { antar individu }\end{array}$ & $\begin{array}{l}\text { Program yang } \\
\text { membaur ke } \\
\text { semua hobi } \\
\text { individu }\end{array}$ & $\begin{array}{c}\text { Program } \\
\text { yang playful }\end{array}$ \\
\hline Bentuk & Playful & $\begin{array}{l}\text { Hobi yang } \\
\text { bervariasi }\end{array}$ & $\begin{array}{c}\text { Memungkinkan ekspresi } \\
\text { hobi }\end{array}$ & $\begin{array}{l}\text { Program untuk } \\
\text { menyalurkan hobi }\end{array}$ & $\begin{array}{l}\text { Keterkaitan } \\
\text { dengan } \\
\text { main } \\
\text { program }\end{array}$ \\
\hline Ekonomi & Playful & $\begin{array}{l}\text { Kebutuhan } \\
\text { Lifestyle yang } \\
\text { berbeda }\end{array}$ & $\begin{array}{l}\text { Membuat antarindividu } \\
\text { mengekspresikannya } \\
\text { dengan individu lainnya }\end{array}$ & $\begin{array}{l}\text { Fungsi yang } \\
\text { memiliki satu } \\
\text { tujuan }\end{array}$ & $\begin{array}{l}\text { Penerapan } \\
\text { tujuan }\end{array}$ \\
\hline Waktu & Playful & $\begin{array}{l}\text { Beda usia beda } \\
\text { karakter }\end{array}$ & $\begin{array}{l}\text { Satu tujuan, topik } \\
\text { obrolan yang satu }\end{array}$ & $\begin{array}{c}\text { Fungsi yang } \\
\text { memungkinkan } \\
\text { perbedaan } \\
\text { karakter berbaur }\end{array}$ & $\begin{array}{c}\text { Fungsi agar } \\
\text { orang } \\
\text { berbeda } \\
\text { karakter } \\
\text { berinteraksi }\end{array}$ \\
\hline
\end{tabular}

Sumber: Dokumen Pribadi, 2020.

Adapun program ruang yang diusulkan secara rinci, sebagai berikut:

Tabel 9. Program ruang
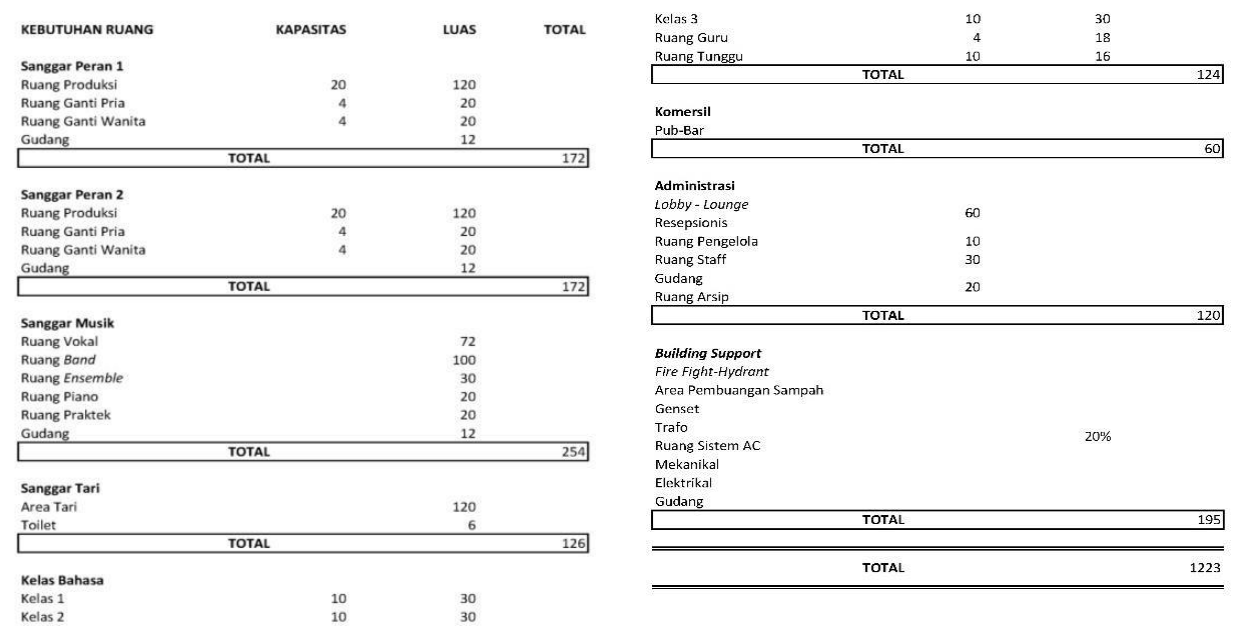

Sumber: Dokumen Pribadi, 2020.

Proses transformasi gubahan massa bangunan yang dilakukan pada proyek Ruang Sosial Interkultural adalah menggunakan media seni tari balet sebagai media pembentukan massa, kemudian dikerucutkan dengan menggunakan kisah cerita Swan Lake yang umum digunakan sebagai koreo dalam gerakan tari balet hingga saat ini. Berikut adalah diagram pemilihan tarian balet dan cerita swan lake sebagai media pembentukan massa: 

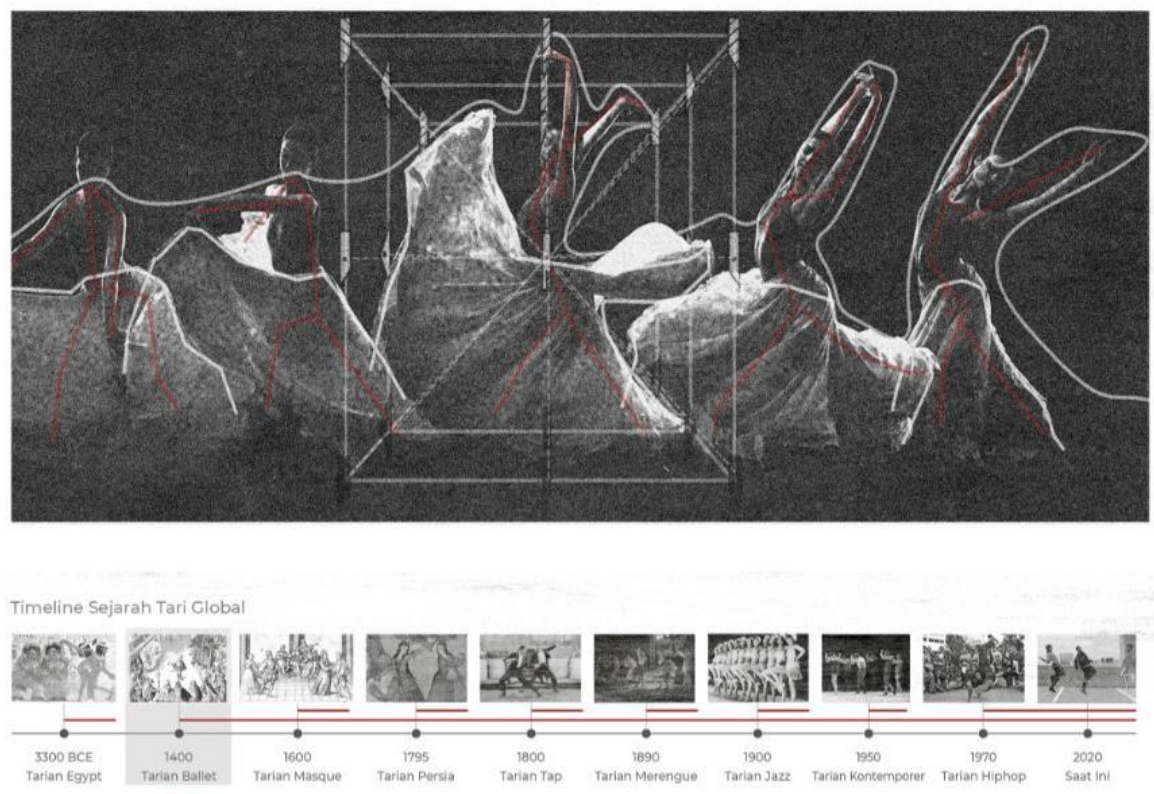

Keterangan: — Pengaruh Kepada Tarian Lain

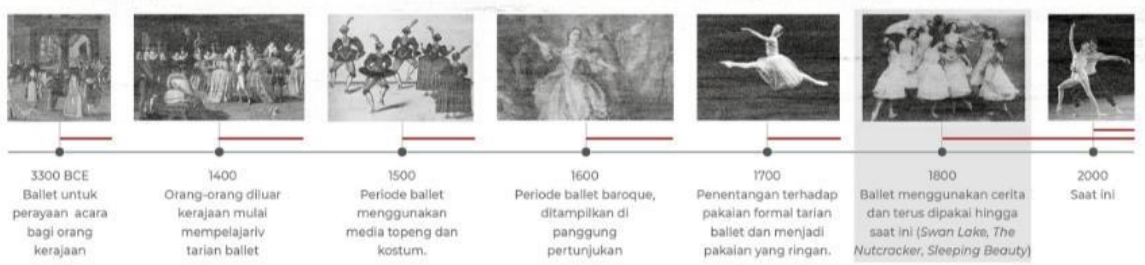

Gambar 3. pemilihan tarian balet dan cerita swan lake sebagai media -pembentukan massa Sumber: Dokumen Pribadi, 2020

Proses selanjutnya adalah melakukan penjabaran alur cerita terhadap kisah cerita swan lake sehingga didapat alur cerita sebagai berikut:

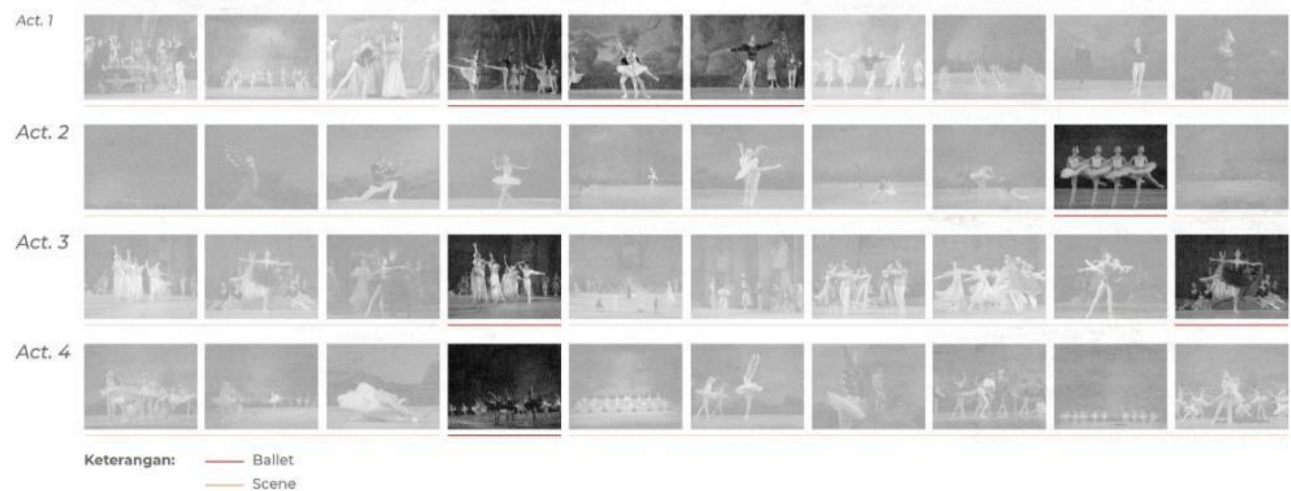

Gambar 4. Diagram alur cerita kisah swan lake Sumber: Dokumen Pribadi, 2020

Notasi laban selanjutnya digunakan sebagai media pembentukan massa. Tari balet pada kisah cerita swan lake diterjemahkan menjadi notasi laban, kemudian dilakukan dekonstruksi terhadap bentuk notasi laban secara 3 dimensi yang disesuaikan dengan visualisasi tari balet pada kisah cerita swan lake. Notasi laban kemudian diberi garis bantuan sebagai media pembentukan massa seperti pada diagram berikut ini: 

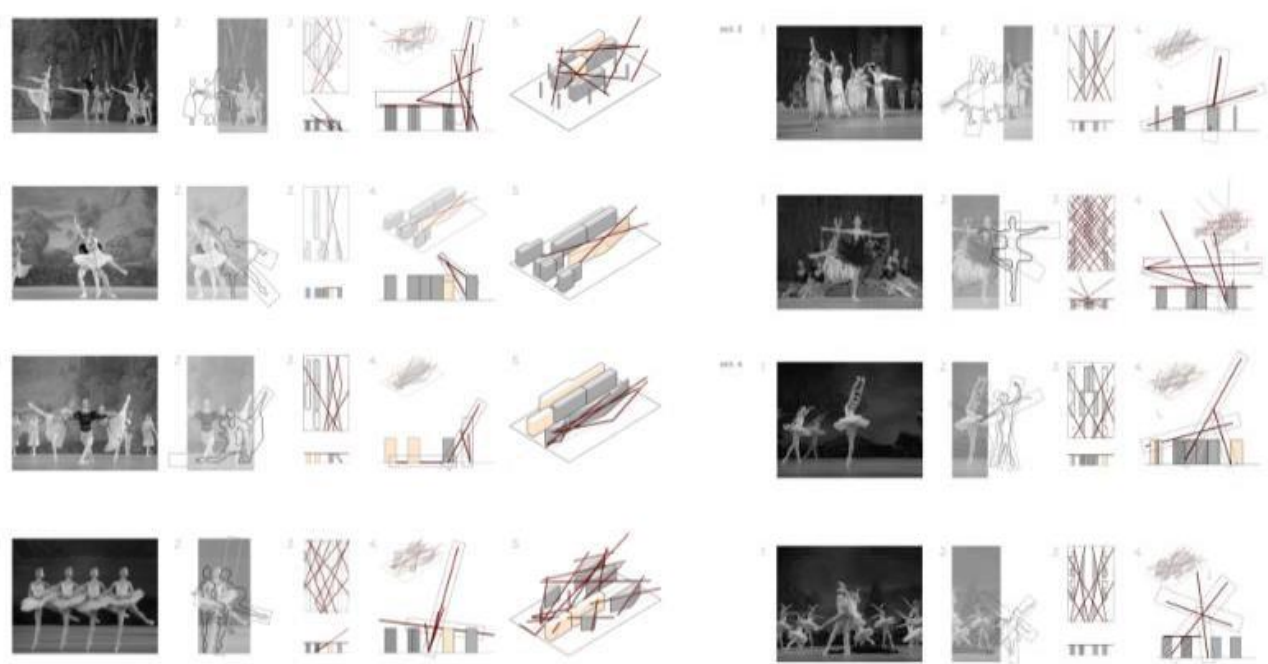

Gambar 5. Diagram terjemahan dan dekonstruksi notasi laban

Sumber: Dokumen Pribadi, 2020

Garis tersebut selanjutnya digabungkan antar scene kisah cerita swan lake, sehingga didapat 4 kombinasi garis sebagai media pembentukan massa bangunan, seperti pada diagram berikut ini:

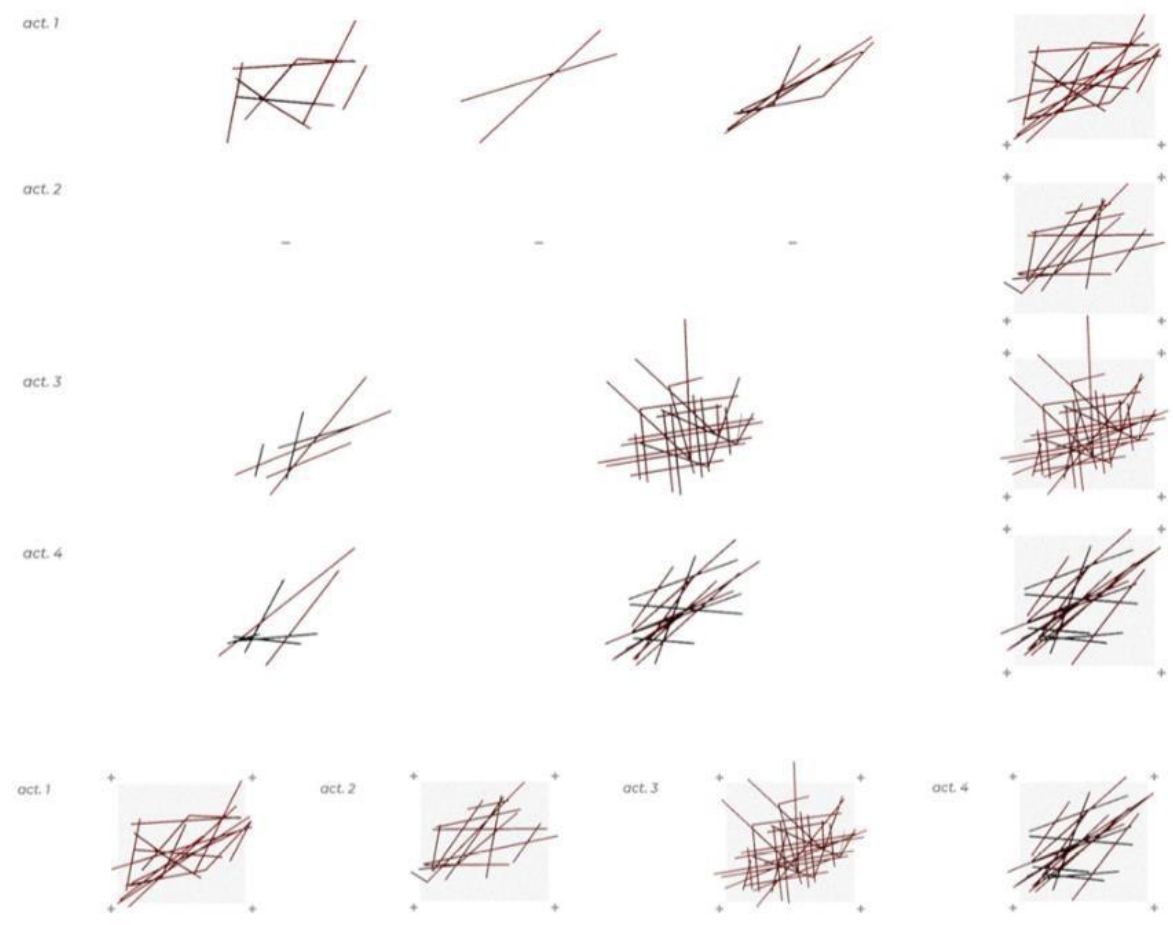

Gambar 6. Diagram penggabungan kombinasi garis notasi laban Sumber: Dokumen Pribadi, 2020.

Kombinasi garis tersebut selanjutnya dilakukan penyesuaian aksis terhadap tapak proyek di Kelurahan Selong. seperti pada diagram berikut: 


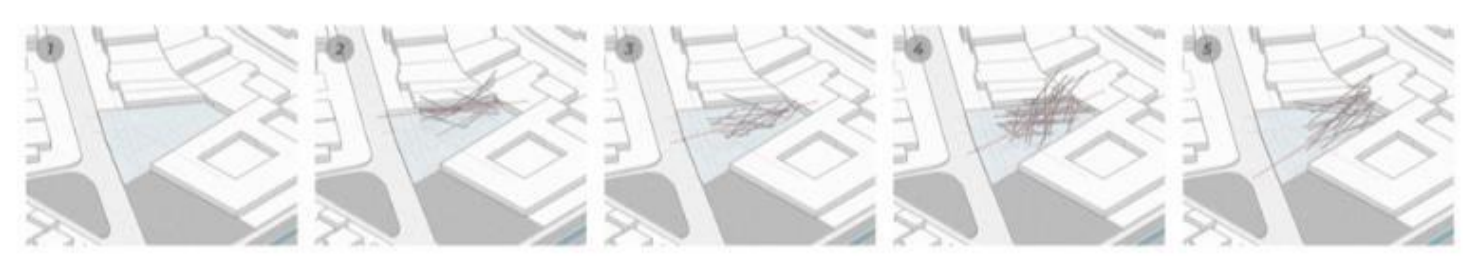

Gambar 7. Diagram penyesuaian kombinasi garis dengan aksis pada tapak Sumber: Dokumen Pribadi, 2020.

Selanjutnya, program ruang diterjemahkan menjadi 3 dimensi untuk disesuaikan dengan bidang yang terbentuk dari gabungan 4 kombinasi garis dari notasi laban kisah cerita swan lake, seperti pada diagram berikut:

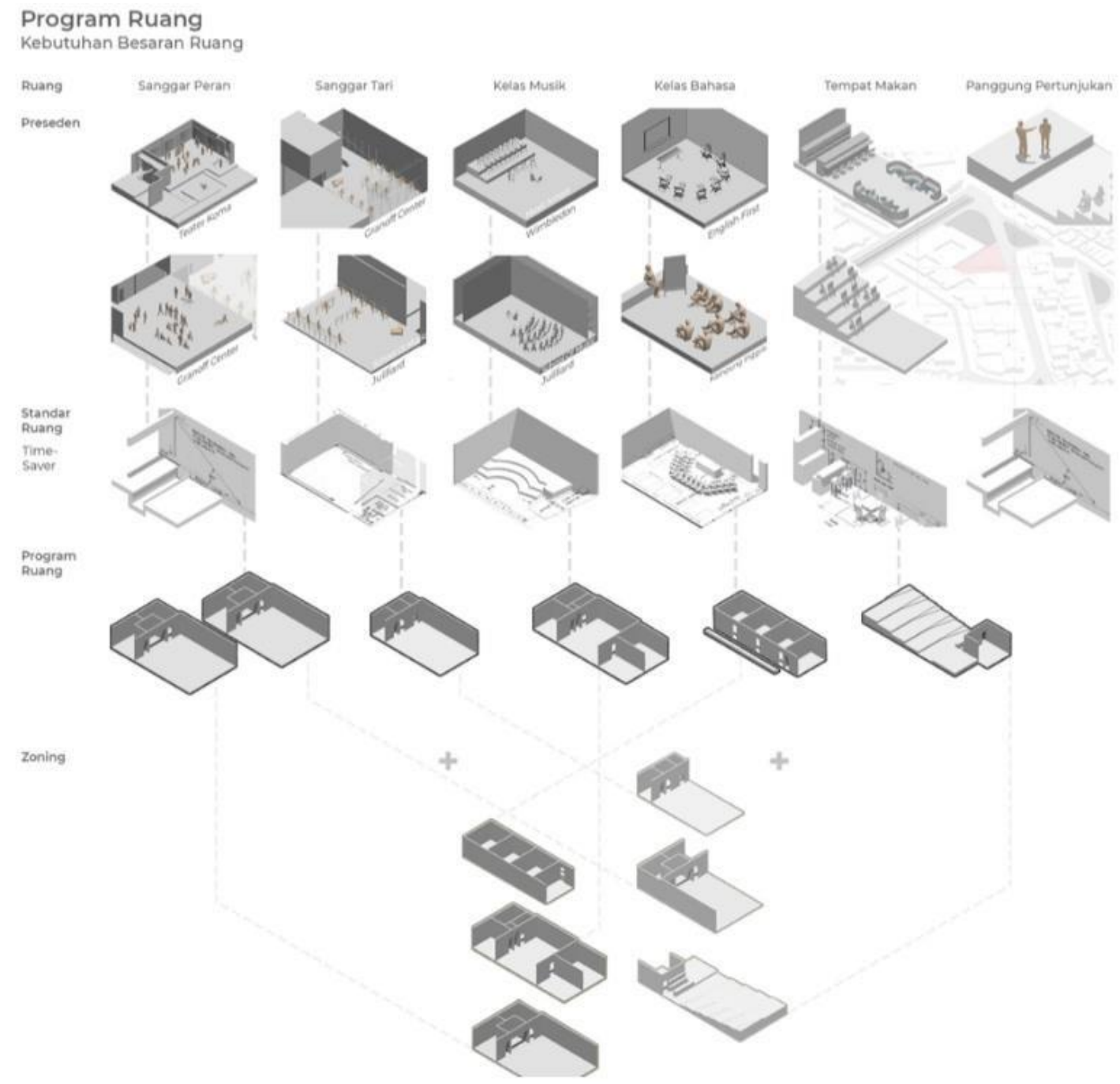

Gambar 8. Diagram terjemahan program ruang secara 3 dimensi Sumber: Dokumen Pribadi, 2020.

Kombinasi garis dari kisah cerita swan lake selanjutnya dijadikan bidang dan terjemahan program yang telah dijadikan 3 dimensi disesuaikan dengan bidang yang terbentuk dengan melakukan superimposisi, seperti pada diagram berikut: 


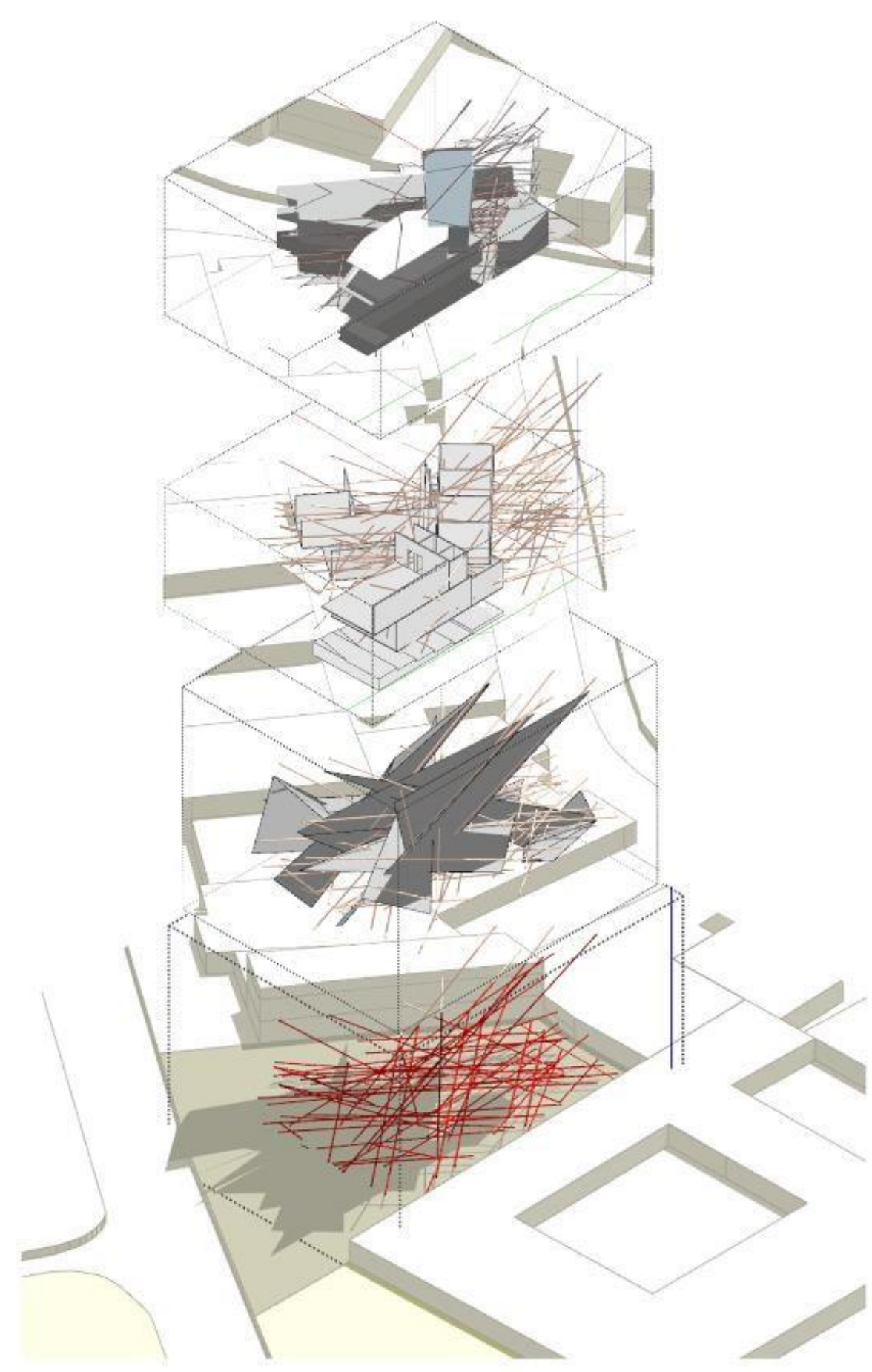

Gambar 9. Diagram superimposisi kombinasi garis dengan program ruang Sumber: Dokumen Pribadi, 2020.

Selubung massa bangunan didapat dari gerakan tari dari kisah cerita Swan Lake dengan terjemahan dari masing-masing kombinasi garis notasi laban yang disesuaikan dengan aksis pada tapak proyek, berikut adalah diagram pembentukan selubung massa bangunan: 


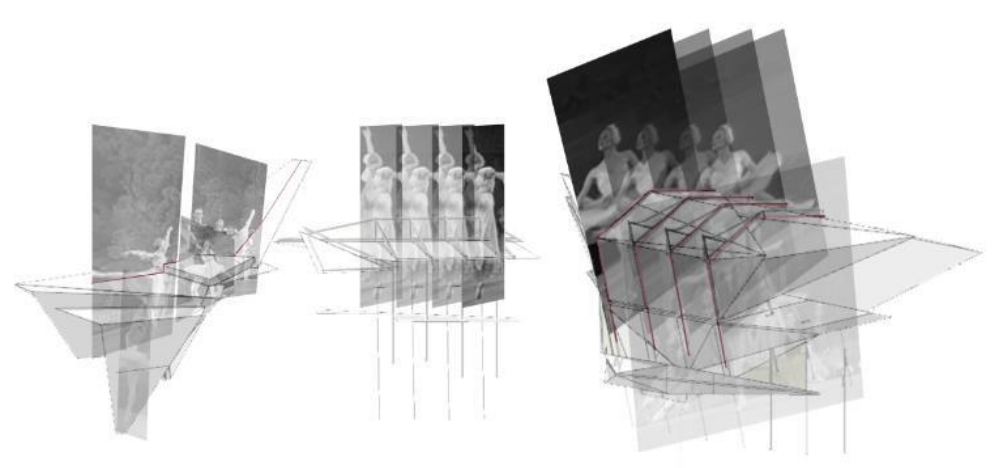

Gambar 10. Diagram pembentukan selubung massa secara konseptual

Sumber: Dokumen Pribadi, 2020
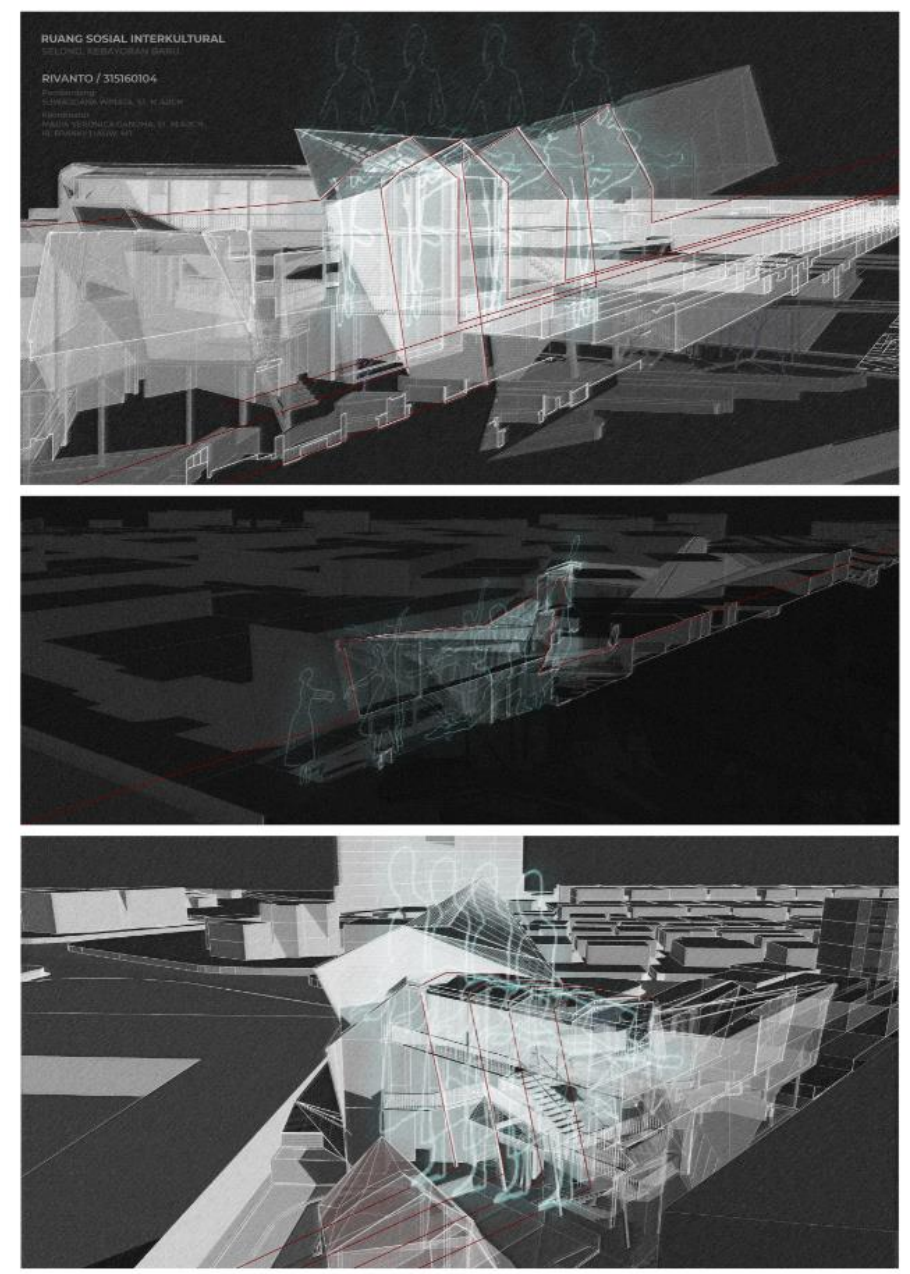

Gambar 11. Diagram pembentukan selubung massa Sumber: Dokumen Pribadi, 2020.

\section{KESIMPULAN DAN SARAN}

Ruang Sosial Interkultural, Kelurahan Selong, Kebayoran Baru, Jakarta Selatan dirancang sebagai wadah berkumpul bagi masyarakat dengan tujuan mempermudah berlangsungnya kegiatan interaksi sosial antar masyarakat yang berada di Kelurahan Selong. Interkultural di dalam masyarakat Kelurahan Selong menjadi isu permasalahan yang diangkat. Permasalahan yang terjadi adalah adanya pandangan etnosentrik antar masyarakat. Pandangan ini membuat jarak sosial antar masyarakat yang mengakibatkan adanya perilaku membeda-bedakan, 
memisahkan, dan adanya fenomena mayoritas dan minoritas. Untuk menciptakan relasi yang baik antar masyarakat Kelurahan Selong, pandangan tersebut harus diubah menjadi pandangan etnorelatif. Dalam merubah pandangan tersebut, digunakan media pembelajaran dengan media seni. Seni pertunjukan digunakan media pembelajaran agar terjadinya interaksi antar masyarakat yang berbeda-beda kebudayaannya. Sehingga, secara tidak langsung berlangsungnya proses pembelajaran trialogis antar masyarakat dan meningkatkan relasi sosial antar masyarakat di Kelurahan Selong. Adapun saran untuk keberlanjutan studi yang akan dilakukan adalah, melakukan kajian lebih lanjut terkait kegiatan pembelajaran sanggar teater dan sanggar tari yang secara maksimal dapat menjadi tempat untuk berinteraksi sosial antar masyarakat di dalamnya dan tetap mempertahankan karakter dari third place.

\section{DAFTAR PUSTAKA}

Barnett, V. (2009). Sample Survey Principles and Methods. John Wiley \& Sons.

Bennet, W. J. (1984). Intercultural Communication Training in Cultural Self-awareness for study abroad. Minneapolis: Unpublished doctoral dissertation.

De Chiara, J. (1984). Time Saver Standards For Residential Development. New York: Mc Graw Hill Book Company.

Dondis, D. A. (1974). A Primer of Visual Literacy. New York: MIT Press.

Gallion, A. B. (1992). Pengantar Perancangan Kota. Jakarta: Erlangga.

Gibberd, F. (1970). Town Design. London: Architectural Press.

Graham, L. (2003). North Town. New York: Boyds Mills Press.

Hakkarainen, K. (2009). A knowledge-practice perspective. Springer.

Jane, J. (1961). The Death and Life of Great American Cities. New York: Vintage.

Jormakka, K. (2003). Basic Design Methods. Birkhäuser Architecture.

Larrice, Michael, Macdonald, \& Elizabeth. (2007). The Urban Design Reader. New York:

Routledge.

Madanipour, A. (2003). Public and Private Spaces of the City. New York: Psychology Press.

Oldenburg, R. (1999). The Great Good Place. New York: Marlowe \& Company.

Pena, W. M., \& Parshall, S. A. (2001). Problem Seeking: An Architectural Programming Primer. New York: John Wiley \& Sons, Inc.

Widasari, P. (2009). Perubahan Fungsi Hunian dan Pengaruhnya Terhadap Kualitas Ruang Kota. 2009: Universitas Indonesia.

Zenner, E., Backus, A., \& Winter-Froemel, E. (2018). Cognitive Contact Linguistics: Placing Usage, Meaning and Mind at the Core of Contact-Induced Variation and Change. Berlin: De Gruyter Mouton. 
